\title{
Early Acute Kidney Injury in Preterm and Term Neonates: Incidence, Outcome, and Associated Clinical Features
}

\author{
Dario Gallo $^{a}$ Karen A. de Bijl-Marcus ${ }^{a}$ Thomas Alderliesten ${ }^{a} \quad$ Marc Lilien $^{b}$ \\ Floris Groenendaal ${ }^{a}$ \\ aDepartment of Neonatology, Wilhelmina Children's Hospital, University Medical Center Utrecht and \\ Utrecht University, Utrecht, The Netherlands; 'bepartment of Paediatric Nephrology, Wilhelmina Children's \\ Hospital, University Medical Center Utrecht and Utrecht University, Utrecht, The Netherlands
}

\section{Keywords}

Early acute kidney injury · Serum Creatinin · Neonatal clinical features $\cdot$ Chronic kidney disease

\begin{abstract}
Background: Critically ill neonates are at high risk of kidney injury, mainly in the first days of life. Acute kidney injury (AKI) may be underdiagnosed due to lack of a uniform definition. In addition, long-term renal follow-up is limited. Objective: To describe incidence, etiology, and outcome of neonates developing AKI within the first week after birth in a cohort of NICU-admitted neonates between 2008 and 2018. Renal function at discharge in infants with early AKI was assessed. Methods and Subjects: AKI was defined as an absolute serum $\mathrm{Cr}(\mathrm{s} C r)$ value above $1.5 \mathrm{mg} / \mathrm{dL}(132 \mu \mathrm{mol} / \mathrm{L})$ after the first $24 \mathrm{~h}$ or as stage 2-3 of the NIDDK neonatal definition. Clinical data and outcomes were collected from medical records and retrospectively analyzed. Results: From January 2008 to December 2018, a total of 9,376 infants were admitted to the NICU of Wilhelmina Children's Hospital/UMC Utrecht, of whom 139 were diagnosed with AKI during the first week after birth. In 72 term infants, the most common
\end{abstract}

etiology was perinatal asphyxia (72.2\%), followed by congenital kidney and urinary tract malformations (CAKUT) (8.3\%), congenital heart disease (6.9\%), and sepsis (2.8\%). Associated conditions in 67 preterm infants were medical treatment of a hemodynamic significant PDA (27.2\%), CAKUT (21\%), and birth asphyxia (19.4\%). Among preterm neonates and neonates with perinatal asphyxia, AKI was mainly diagnosed by the $\mathrm{s} C r>1.5 \mathrm{mg} / \mathrm{dL}$ criterion. Renal function at discharge improved in 76 neonates with AKI associated with acquired conditions. Neonates with stage 3 AKI showed increased sCr values at discharge. Half of these were caused by congenital kidney malformations and evolved into chronic kidney disease (CKD) later in life. Neurodevelopmental outcome (NDO) at 2 years was favorable in 93\% of surviving neonates with detailed follow-up. Conclusion: During the first week after birth, AKI was seen in $1.5 \%$ of infants admitted to a level III NICU. Renal function at discharge had improved in most neonates with acquired AKI but not in infants diagnosed with stage $3 \mathrm{AKI}$. Long-term renal function needs further exploration, whereas NDO appears to be good.

(c) 2021 The Author(s) Published by S. Karger AG, Basel karger@karger.com www.karger.com/neo

Karger"

GOPEN ACCESS
(C) 2021 The Author(s)

Published by S. Karger AG, Basel

This is an Open Access article licensed under the Creative Commons Attribution-NonCommercial-4.0 International License (CC BY-NC) (http://www.karger.com/Services/OpenAccessLicense), applicable to the online version of the article only. Usage and distribution for commercial purposes requires written permission.
Floris Groenendaal

Department of Neonatology, Wilhelmina Children's Hospital University Medical Center Utrecht

KE.04.123.1, Lundlaan 6, NL-3584 EA Utrecht (The Netherlands)

F.Groenendaal@umcutrecht.nl 


\section{Introduction}

Acute kidney injury (AKI) is defined by an acute reduction of kidney function, resulting in uremia, altered fluid balance, and disturbed electrolytes homeostasis. In critically ill neonates, AKI is relatively common and occurs mainly in the first days of life, secondary to hypovolemia, hypotension, and ischemia, and less frequently to primary kidney disease [1]. AKI has been traditionally defined as an increase of serum $\mathrm{Cr}(\mathrm{sCr})$ above $1.5 \mathrm{mg} / \mathrm{dL}$ $(132 \mu \mathrm{mol} / \mathrm{L})$ [2-7].

From 2008, the RIFLE criteria have been adapted to neonates from older infants and adults, after reports stating that residual damage might occur even after a small increase in $\mathrm{sCr}$, evolving into CKD later in life [8]. Using the adapted criteria, the incidence of AKI has become higher, but long-term renal follow-up is scarce [9]. In older children, a 2- or 3-fold rise of sCr from baseline (stage $2-3 \mathrm{AKI}$ ) is associated with increased mortality and morbidity [10].

Moreover, diagnosis of AKI in the first days after birth is cumbersome, due to developing renal physiology and unreliable assessment of diuresis. In the present study, we

Table 1. Neonatal clinical features

\begin{tabular}{|c|c|c|}
\hline & $\begin{array}{l}\text { Preterm }(n=67), \\
n(\%)\end{array}$ & $\begin{array}{l}\text { Term }(n=72), \\
n(\%)\end{array}$ \\
\hline GA, wk $($ mean $\pm S D)$ & $30.5 \pm 4.0$ & $39.2 \pm 1.0$ \\
\hline$<28$ wk & $25(37.3)$ & \\
\hline$<1,000 \mathrm{~g}$ & $21(31.3)$ & \\
\hline Sex (male) & $44(65.7)$ & $46(63.9)$ \\
\hline Birth weight, g (mean \pm SD) & $1,658 \pm 841$ & $3,398 \pm 461$ \\
\hline \multicolumn{3}{|l|}{ Mode of birth } \\
\hline Spontaneous vaginal & $17(25.4)$ & $29(40.3)$ \\
\hline Vacuum & $1(1.5)$ & $8(11.1)$ \\
\hline Caesarean section & $49(73.1)$ & $35(48.6)$ \\
\hline Twin & $16(23.9)$ & $2(2.8)$ \\
\hline \multicolumn{3}{|l|}{ Maternal disease } \\
\hline Preeclampsia & $11(16.4)$ & $4(5.6)$ \\
\hline Sentinel event at birth & $8(11.9)$ & $17(23.6)$ \\
\hline Oligo/anhydramnion & $9(13.4)$ & $7(9.7)$ \\
\hline \multicolumn{3}{|l|}{ Apgar score (median, IQR) } \\
\hline $1 \mathrm{~min}$ & $5(4)$ & $2(4)$ \\
\hline $5 \mathrm{~min}$ & $7(4)$ & $5(5)$ \\
\hline \multicolumn{3}{|l|}{ Resuscitation } \\
\hline (chest compression) & $8(11.9)$ & $21(29.2)$ \\
\hline Small for GA $(<2 \mathrm{SD})$ & $5(7.5)$ & \\
\hline Mechanical ventilation & $39(58.2)$ & $40(55.6)$ \\
\hline Inotropes & $30(44.8)$ & $39(54.2)$ \\
\hline
\end{tabular}

GA, gestational age.

Early Acute Neonatal Kidney Injury aim to describe incidence, etiology, and outcomes of neonates developing AKI within the first week after birth in a cohort of neonates born between 2008 and 2018. Renal function at discharge in these infants as well as neurodevelopmental outcome (NDO) were assessed. The clinical description of a patient cohort can be used to tailor a screening protocol for AKI and serve as the foundation for a renal follow-up program in the NICU.

\section{Patients and Methods}

From January 2008 to December 2018, a total of 9,376 neonates was admitted to the NICU of Wilhelmina Children's Hospital/ University Medical Center Utrecht. These neonates were eligible for this retrospective study.

Infants admitted to the NICU had daily blood sampling for blood gases, electrolytes, glucose, and hematological examinations. At least one sCr measurement was obtained in case of reduced urinary output $(<1 \mathrm{~mL} / \mathrm{kg} / \mathrm{h}$ over $12 \mathrm{~h})$ in preterm infants and in term infants with clinical concerns. In all infants with AKI, the last sCr level before discharge was noted. In our NICU, early AKI was defined as a $\mathrm{sCr}$ above $1.5 \mathrm{mg} / \mathrm{dL}(132 \mu \mathrm{mol} / \mathrm{L})$ after the first $24 \mathrm{~h}$ of life, despite a normal maternal renal function, in the first week after birth $[2,3]$. In addition, AKI was defined as stage $2-3$ of NIDDK neonatal definition. Stage 2 was identified by a 2-2.9-fold increase of sCr from baseline, while stage 3 by a 3 -fold increase or a $\mathrm{sCr}>2.5 \mathrm{mg} / \mathrm{dL}(221 \mu \mathrm{mol} / \mathrm{L})$ [8]. Preterm and fullterm infants were analyzed separately. Clinical features and out-

Table 2. Clinical factors in preterm and term infants with AKI

\begin{tabular}{lcc}
\hline & $\begin{array}{l}\text { Preterm } \\
(n=67), \\
n(\%)\end{array}$ & $\begin{array}{l}\text { Term } \\
(n=72), \\
n(\%)\end{array}$ \\
\hline CAKUT & $14(20.9)$ & $6(8.3)$ \\
Syndrome & $5(7.5)$ & $3(4.2)$ \\
Perinatal asphyxia & $13(19.4)$ & $52(72.2)$ \\
$\quad$ HIE with TH & $8(11.9)^{*}$ & $34(47.2)$ \\
Congenital heart disease & $2(3.0)$ & $5(6.9)$ \\
Aortic/renal artery thrombosis & $3(4.5)$ & $1(1.4)$ \\
Sepsis & $2(3.0)$ & $2(2.8)$ \\
NEC & $1(1.5)$ & $1(1.4)$ \\
PDA NSAID treatment & $18(26.9)$ & \\
$\quad$ Indomethacin & $17(25.4)$ & \\
Ibuprofen & $1(1.5)$ & \\
Gentamycin and/or vancomycin & $14(20.9)$ & $8(11.1)$ \\
No associated conditions & $12(17.9)$ & $3(4.2)$ \\
\hline
\end{tabular}

AKI, acute kidney injury; CAKUT, congenital kidney and urinary tract malformations; HIE, hypoxic-ischemic encephalopathy; $\mathrm{TH}$, therapeutic hypothermia; NEC, necrotizing enterocolitis; PDA, persistent ductus arteriosus; NSAID, non-steroid anti-inflammatory drug. * These preterm infants had a gestational age of 35-36 weeks. 
comes were arranged according to etiology and AKI categorization. The following clinical data were collected from medical records: maternal disease (such as preeclampsia), presence of oligo/ anhydramnion, gestational age (GA), birth weight, sex, mode of delivery, multiple birth, Apgar scores (AS) at 1 and $5 \mathrm{~min}$, resuscitation, and need for mechanical ventilation. Risk factors for AKI were explored, including need for inotropes for hemodynamic instability, use of nephrotoxic drugs such as gentamycin and vancomycin, and the following neonatal conditions: perinatal asphyxia, congenital kidney and urinary tract malformations (CAKUT), congenital heart disease (CHD), treatment for hemodynamic significant patent ductus arteriosus with ibuprofen/indomethacin (NSAID) or surgical closure, arterial thrombosis, sepsis, and necrotizing enterocolitis.

Perinatal asphyxia was defined as persistence of an Apgar score $<5$ at $10 \mathrm{~min}$ or severe acidosis in umbilical cord blood gas $(\mathrm{pH}$ $<7.00$ or $\mathrm{BE}<-16 \mathrm{mmol} / \mathrm{L}$ ). Routine assessment of NDO was performed in term infants with hypoxic ischemic encephalopathy and in preterm infants with a $\mathrm{GA}<30.0$ weeks or a birth weight $<1,000$ grams. NDO included the Griffiths' Mental Development Scales (GMDS) at 15 months and the Bayley Scales of Infant and Toddler Development Third Edition (BSID-III) at 24 months. From the BSID-III, only the cognitive (CS) and motor scales (MS) were assessed.

\section{Statistical Analysis}

Statistical analysis was performed using IBM SPSS v 21.0 (Chicago, IL). Data were described as percentages, mean $\pm \mathrm{SD}$, and median \pm IQR where appropriate. Renal function was described as mean $\mathrm{sCr} \pm \mathrm{SD}$ value.

Student $t$ tests or Kruskal-Wallis tests were used where appropriate. Differences were considered statistically significant at alpha 0.05 .

\section{Results}

Of the 9,376 infants admitted to the NICU over the study period, 139 (1.5\%) developed AKI in the first week after birth, of whom 72 (52\%) were born at term and 67 (48\%) preterm.

Neonatal clinical characteristics are summarized in Table 1.

\section{Etiology}

Among all neonates with early AKI, 14\% had CAKUT, $81 \%$ developed AKI in association to acquired conditions, and an additional 5\% because of congenital heart disease. The most frequent potential causes in preterm and full-term infants are reported in Table 2. Genetic syndromes were diagnosed in 8 infants, of which 4 cases had kidney malformations. Arterial thrombosis of the aorta and subsequent renal ischemia resulted from umbilical artery catheterization in all cases. In Table 3, the main clinical factors are related to AKI definition and staging.

\section{Outcomes}

Outcomes were analyzed separately for infants diagnosed with AKI stages 2 and 3 and with $1.5 \mathrm{mg} / \mathrm{dL}$ criterion. Serum $\mathrm{Cr}$ values at discharge are reported in $\mathrm{Ta}-$ ble 4 . Renal function had improved in 35 term and 41 preterm infants, whereas neonates with AKI stage 3

Table 3. Main clinical factors related to definition of AKI

\begin{tabular}{lrrcccc}
\hline & Preterm & CAKUT & $\begin{array}{l}\text { Perinatal } \\
\text { asphyxia }\end{array}$ & HIE with TH & CHD & PDA treatment \\
\hline Stage $2, n(\%)$ & $12(18)$ & $4(20)$ & $4(6)$ & $3(7)$ & $2(30)$ & $3(17)$ \\
Stage $3, n(\%)$ & $8(12)$ & $11(55)$ & $11(17)$ & $6(14)$ & $1(13)$ & \\
$>1.5 \mathrm{mg} / \mathrm{dL}, n(\%)$ & $47(70)$ & $5(25)$ & $50(77)$ & $33(79)$ & $4(57)$ & $15(83)$ \\
\hline
\end{tabular}

AKI, acute kidney injury; CAKUT, congenital kidney and urinary tract malformations; HIE, hypoxic-ischemic encephalopathy; $\mathrm{TH}$, therapeutic hypothermia; $\mathrm{CHD}$, congenital heart disease; PDA, persistent ductus arteriosus.

Table 4. $\mathrm{sCr}$ values $(\mathrm{mg} / \mathrm{dL})$ at discharge from the neonatal unit for preterm and full-term infants according to the definition of AKI

\begin{tabular}{lllll}
\hline & Stage 2 & Stage 3 & $>1.5 \mathrm{mg} / \mathrm{dL}$ & $p$ value \\
\hline Full term & $0.44 \pm 0.05, n=3$ & $1.73 \pm 0.9, n=10$ & $0.66 \pm 0.29, n=32$ & $<0.01$ \\
Preterm & $0.64 \pm 0.23, n=10$ & $4.09 \pm 1.7, n=6$ & $0.61 \pm 0.32, n=31$ & $<0.01$ \\
\hline
\end{tabular}

sCr, serum Cr; AKI, acute kidney injury. 
showed significantly increased $\mathrm{sCr}$ values at discharge from the NICU. Table 5 reports follow-up data. NDO for term and preterm infants is described in Table 6.

Among infants with acquired AKI diagnosed by 1.5 $\mathrm{mg} / \mathrm{dL}$ criterion, 2 term asphyxiated neonates developed cerebral palsy and deafness, and 3 preterm neonates had a Griffiths' score at 15-18 months $<-1$ SD $(<88)$; however, only in 1 patient neurodevelopment delay was persistent using the BSID-III at 2 years of age.

\section{Discussion}

Critically ill neonates in the NICU are at high risk of AKI due to associated comorbidity, fluid and blood pressure imbalance, and nephrotoxic drug exposure [11]. In the present study, we assessed the incidence of AKI and outcome

Table 5. Follow-up data

\begin{tabular}{llll}
\hline & $\begin{array}{l}\text { Stage 2 } \\
(n=15), \\
n(\%)\end{array}$ & $\begin{array}{l}\text { Stage 3 } \\
n=21), \\
n(\%)\end{array}$ & $\begin{array}{l}>1.5 \mathrm{mg} / \mathrm{dL} \\
(n=103), \\
n(\%)\end{array}$ \\
\hline Died & $2(13.3)$ & $4(19)$ & $35(34)$ \\
Surviving & 13 & 17 & 68 \\
CKD $^{*}$ & $2(15.4)$ & $9(53)$ & $2(2.9)$ \\
BPD* $_{\text {Brain injury* }}$ & $2(15.4)$ & 0 & $7(10.3)$ \\
$\quad$ Cystic PVL & $2(15.4)$ & $4(23.5)$ & $20(29.4)$ \\
$\quad$ IVH & $1(7.7)$ & 0 & $2(2.9)$ \\
Perinatal asphyxia & $1(7.7)$ & 0 & $10(14.7)$ \\
& 0 & $4(23.5)$ & $8(11.8)$ \\
\hline
\end{tabular}

PVL, periventricular leukomalacia; IVH, intraventricular hemorrhage; BPD, bronchopulmonary dysplasia; CKD, chronic kidney disease. ${ }^{*}$ Percentages of surviving infants. in a cohort of term and preterm neonates. AKI was defined using a combination of 2 definitions. Given the limits of $\mathrm{s} C \mathrm{r}$ as a measure of kidney function, particularly in the first week after birth [12], we used a sCr cutoff of $1.5 \mathrm{mg} / \mathrm{dL}$ [2-4]. This clinical definition describes a severe kidney impairment and is still adopted in research articles [5-7]. Among neonates with perinatal asphyxia, it showed a positive predictive value for an adverse outcome [13].

Furthermore, AKI was defined as stage 2-3 of NIDDK neonatal AKI workshop [8]. In the present study, we did not include patients with AKI stage 1 because of the scarce evidence that such mild AKI is associated with long-term consequences $[14,15]$, whereas its incidence in the NICU is quite high [16].

Of our NICU-admitted patients, 139 (1.5\%) developed AKI, of whom 20 (14\%) had CAKUT. Using the sCr 1.5 $\mathrm{mg} / \mathrm{dL}$ criterion, Agras et al. [3] and Mortazavi et al. [4] reported incidences of 3.4 and $2.6 \%$, respectively. Our percentage of infants with AKI is slightly lower, and this might be caused by our focus on AKI in the first week after birth. In contrast, Charlton et al. [16] in the "AWAKEN" cohort diagnosed early AKI according to the KDIGO definition from stage 1 and found, among all enrolled infants, a higher incidence of $11 \%$.

In line with previous reports, in our cohort of neonates, AKI was more often the result of acquired as opposed to congenital abnormalities [3]. Perinatal asphyxia was the most frequent associated condition in term neonates with AKI. Several studies confirm the high prevalence of AKI in asphyxiated neonates, as high as $72 \%$ by Hankins et al. [17], 54\% by Gupta et al. [18], and 29.5\% by Bozkurt and Yucesoy [19]. In more than $70 \%$ of asphyxiated neonates of our cohort, AKI was diagnosed by the $1.5 \mathrm{mg} / \mathrm{dL}$ criterion. This can be explained in the context of early kidney injury, as the first measured sCr value

Table 6. Neurodevelopmental outcome (mean \pm SD)

\begin{tabular}{|c|c|c|c|}
\hline Full-term infants & Stage $2(n=2)$ & Stage $3(n=4)$ & $>1.5 \mathrm{mg} / \mathrm{dL}(n=14)$ \\
\hline $\begin{array}{l}\text { Griffiths } 15-18 \text { months } \\
\text { BSID } 2 \text { yr cognition } \\
\text { BSID } 2 \text { yr motor } \\
\text { Adverse }\end{array}$ & $\begin{array}{l}96 \pm 6(n=2) \\
145(n=1) \\
133(n=1)\end{array}$ & $\begin{array}{r}102 \pm 7(n=4) \\
97 \pm 6(n=3) \\
111 \pm 1(n=2)\end{array}$ & $\begin{array}{l}94 \pm 10(n=14) \\
109 \pm 9(n=9) \\
118 \pm 14(n=9) \\
2(1 \text { deafness and } 1 \text { cerebal palsy })\end{array}$ \\
\hline Preterm infants & Stage $2(n=5)$ & Stage $3(n=1)$ & $>1.5 \mathrm{mg} / \mathrm{dL}(n=16)$ \\
\hline $\begin{array}{l}\text { Griffiths } 15-18 \text { months } \\
\text { BSID } 2 \text { yr cognition } \\
\text { BSID } 2 \text { yr motor } \\
\text { Adverse }\end{array}$ & $\begin{array}{l}93 \pm 15(n=5) \\
115 \pm 0(n=2) \\
115 \pm 12(n=2)\end{array}$ & $85(n=1)$ & $\begin{array}{r}96 \pm 12(n=16) \\
104 \pm 12(n=17) \\
108 \pm 13(n=15) \\
1 \text { (neurodevelopmental impairment) }\end{array}$ \\
\hline
\end{tabular}


after birth can already be increased without a previous value to relate to.

Conversely, among infants with congenital anomalies of the kidney and urinary tract, more than half had stage 3 AKI, hence showing a severe kidney impairment. All patients had a prenatal diagnosis, and oligo/anhydramnion was present in case of bilateral kidney involvement [20].

In the majority of cases (53\%), the presence of the posterior urethral valves or bilateral kidney dysplasia led to CKD (stage II-V), with 2 infants requiring dialysis after the neonatal period and later kidney transplant. In the present study, a relatively high percentage of preterm infants were born before 28 weeks of gestation, as according to a national protocol, all infants with a GA below 32 weeks are treated in level III NICUs in the Netherlands.

In these extremely preterm born infants, AKI was more frequently associated with the treatment of a hemodynamic significant PDA. AKI may result as an adverse effect of indomethacin administration and, in our cohort, indomethacin was used as a first-line therapy until 2016. In line with the literature, we find that a renal insult was common in more premature neonates [21]. However, $\mathrm{sCr}$ values did not reach $2.5 \mathrm{mg} / \mathrm{dL}$ as for AKI stage 3, except for infants with congenital AKI. Congenital heart disease due to coarctation of the aorta, aortic arch interruption, hypoplastic left heart syndrome, and transposition of the great arteries caused AKI as a result of systemic hypoperfusion [22]. Sepsis was a minor cause of AKI in both preterm and term neonates, in contrast with findings of Agras et al. [3] and Bolat et al. [6]. However, we looked only at early onset sepsis related to kidney injury in the first week, and the incidence of early onset sepsis in our population is low. Since long-term follow-up of renal function is missing, we assessed the last $\mathrm{sCr}$ before discharge as a measure of kidney function. As expected, infants with AKI stage 3 still had significantly increased $\mathrm{sCr}$ at discharge from the NICU and half of the patients developed CKD later in life. In infants diagnosed as stage 2 or with $1.5 \mathrm{mg} /$ $\mathrm{dL}$ criterion, renal function had improved at the time they could be discharged from the NICU although normal sCr values were not reached in all. In most cases, AKI was the result of systemic disease. This is reflected in the number of patients with an adverse outcome, in addition to a high mortality (35\%), high incidence of bronchopulmonary dysplasia (9\%), and brain injury (27\%).

Previous studies reported that in infants with birth asphyxia, AKI could be associated with short-term neurological outcome $[23,24]$. However, in our cohort, NDO at 2 years of age was favorable almost in all cases, including neonates with AKI due to asphyxia, and independent- ly from AKI categorization. Furthermore, the clinical management of AKI was conservative in all but 3 infants.

The study has several limitations. First, this is a monocentric retrospective study. Neonatal sCr levels are not assessed routinely in the first days after birth of otherwise healthy neonates and are not part of the point of care of preterm infants, in order to minimize blood loss. Furthermore, $\mathrm{sCr}$ is a poor marker of renal damage. Recent studies have looked at more specific and sensitive markers, like NGAL and KIM1 in urine, although there is yet very little evidence in neonates [25]. Thus, we may have underestimated the prevalence of AKI in our population. However, sCr levels are measured during the first week after birth in at least $40 \%$ of neonates who were admitted to our level III NICU. In addition, since most full-term infants with congenital heart malformations are not admitted to the NICU but to the PICU in our hospital, the percentage of infants with AKI in full-term infants might be somewhat higher. To date, a uniform definition of AKI is still lacking, and, in the first week after birth, it needs to consider the developing renal physiology $[26,27]$. We acknowledge that using a different definition of AKI could change its incidence in our population. Finally, we would like to emphasize that in our center, as in most NICUs, there is not a renal follow-up program for neonates with AKI.

Our study shows that, with the exception of infants with CAKUT, the majority of infants are discharged from the NICU with an improving sCr. However, we are not able to make predictions on long-term kidney function of these patients. NDO of our cohort was within the normal range in most high-risk infants with detailed follow-up examination of neurodevelopment.

Assessment of renal outcome in the NICU is relevant. Ideally, measurement of sCr level, blood pressure, renal protein excretion, and tubular function testing should be performed. Further studies are needed to define the optimal timing of these follow-up assessments [28].

\section{Conclusions and Future Perspectives}

The study provides an overview of AKI occurring in the early clinical course of neonates admitted to a level III NICU. Neonates with acquired AKI were generally severely ill and AKI is associated with high morbidity and mortality of both preterm and term infants. Episodes of AKI were generally transient and self-limiting and were mainly diagnosed by $1.5 \mathrm{mg} / \mathrm{dL}$ criterion.

The clinical management was conservative almost in all cases, although normal levels of sCr were not seen in 
all infants at discharge. In contrast, infants with AKI stage 3 had significantly increased $\mathrm{sCr}$, confirming them to be at high risk of renal sequelae. A renal follow-up program in the NICU is needed; further studies will define the optimal timing for assessment.

\section{Statement of Ethics}

The study was approved by the Ethics Committee of the University Medical Center Utrecht. Written parental informed consent was waived for the research purpose, reporting anonymized data.

\section{Conflict of Interest Statement}

The authors have no conflicts of interest to disclose.

\section{Funding Sources}

For this study, a grant was obtained from the Stichting Neonatale Neurologie Utrecht (www.snnu.nl) to cover the costs of publication.

\section{Author Contributions}

Dario Gallo, Thomas Alderliesten, and Floris Groenendaal designed the study and performed the analyses. Dario Gallo has written the manuscript. All authors have read and contributed to the final version of the manuscript.

\section{References}

1 Selewski DT, Charlton JR, Jetton JG, Guillet R, Mhanna MJ, Askenazi DJ, et al. Neonatal acute kidney injury. Pediatrics. 2015;136(2): e463-73.

2 Gouyon JB, Guignard JP. Management of acute renal failure in newborns. Pediatr Nephrol. 2000 Sep;14(10-11):1037-44.

3 Agras PI, Tarcan A, Baskin E, Cengiz N, Gürakan B, Saatci U. Acute renal failure in the neonatal period. Ren Fail. 2004;26(3):305-9.

4 Mortazavi F, Hosseinpour Sakha S, Nejati N. Acute kidney failure in neonatal period. Iran J Kidney Dis. 2009;3(3):136-40.

5 Viswanathan S, Manyam B, Azhibekov T, Mhanna MJ. Risk factors associated with acute kidney injury in extremely low birth weight (ELBW) infants. Pediatr Nephrol. 2012;27(2):303-11.

6 Bolat F, Comert S, Bolat G, Kucuk O, Can E, Bulbul A, et al. Acute kidney injury in a single neonatal intensive care unit in Turkey. World J Pediatr. 2013;9(4):323-9.

7 Bansal SC, Nimbalkar AS, Kungwani AR, Patel DV, Sethi AR, Nimbalkar SM. Clinical profile and outcome of newborns with acute kidney injury in a level 3 neonatal unit in western India. J Clin Diagn Res. 2017;11(3):SC01-4.

8 Zappitelli M, Ambalavanan N, Askenazi DJ, Moxey-mims MM, Kimmel PL, Star RA, et al. Developing a neonatal acute kidney injury research definition: a report from the NIDDK neonatal AKI workshop. Pediatr Res. 2017; 82(4):569-73.

9 Jetton JG, Boohaker LJ, Sethi SK, Wazir S, Rohatgi S, Soranno DE, et al. Neonatal Kidney Collaborative (NKC). Incidence and outcomes of neonatal acute kidney injury (AWAKEN): a multicentre, multinational, observational cohort study. Lancet Child Adolesc Health. 2017 Nov;1(3):184-94.

10 Mammen C, Al Abbas A, Skippen P, Nadel H Levine D, Collet JP, et al. Long-term risk of CKD in children surviving episodes of acute kidney injury in the intensive care unit: a prospective cohort study. Am J Kidney Dis. 2012; 59(4):523-30.
11 Bellomo R, Ronco C, Kellum JA, Mehta RL, Palevsky P. Acute renal failure: definition, outcome measures, animal models, fluid therapy and information technology needs: the second international consensus conference of the acute dialysis quality initiative (ADQI) group. Crit Care. 2004;8(4):R204-12.

12 Boer DP, De Rijke YB, Hop WC, Cransberg K, Dorresteijn EM. Reference values for serum creatinine in children younger than 1 year of age. Pediatr Nephrol. 2010;25(10):2107-13

13 Aggarwal A, Kumar P, Chowdhary G, Majumdar S, Narang A. Evaluation of renal functions in asphyxiated newborns. J Trop Pediatr. 2005;51(5):295-9.

14 Weintraub AS, Connors J, Carey A, Blanco V, Green RS. The spectrum of onset of acute kidney injury in premature infants less than 30 weeks gestation. J Perinatol. 2016;36(6):47480.

15 Maqsood S, Fung N, Chowdhary V, Raina R, Mhanna MJ. Outcome of extremely low birth weight infants with a history of neonatal acute kidney injury. Pediatr Nephrol. 2017;32(6): 1035-43.

16 Charlton JR, Boohaker L, Askenazi D, Brophy PD, D’Angio C, Fuloria M, et al. Incidence and risk factors of early onset neonatal AKI. Clin J Am Soc Nephrol. 2019;14(2):184-95.

17 Hankins GD, Koen S, Gei AF, Lopez SM, Van Hook JW, Anderson GD. Neonatal organ system injury in acute birth asphyxia sufficient to result in neonatal encephalopathy. Obstet Gynecol. 2002;99(5 Pt 1):688-91.

18 Gupta C, Massaro AN, Ray PE. A new approach to define acute kidney injury in term newborns with hypoxic ischemic encephalopathy. Pediatr Nephrol. 2016;31(7):1167-78.

19 Bozkurt O, Yucesoy E. Acute kidney injury in neonates with perinatal asphyxia receiving therapeutic hypothermia. Am J Perinatol. 2020 Jan 27.

20 Rodriguez MM. Congenital anomalies of the kidney and the urinary tract (CAKUT). Fetal Pediatr Pathol. 2014 Oct-Dec;33(5-6):293320.
21 Mitra S, Florez ID, Tamayo ME, Mbuagbaw L, Vanniyasingam T, Veroniki AA, et al. Association of placebo, indomethacin, ibuprofen, and acetaminophen with closure of hemodynamically significant patent ductus arteriosus in preterm infants. JAMA. 2018; 319(12):1221-38

22 Agras PI, Derbent M, Ozcay F, Baskin E, Turkoglu S, Aldemir D, et al. Effect of congenital heart disease on renal function in childhood. Nephron Physiol. 2005;99(1): p10-5.

23 Sarkar S, Askenazi DJ, Jordan BK, Bhagat I, Bapuraj JR, Dechert RE, et al. Relationship between acute kidney injury and brain MRI findings in asphyxiated newborns after therapeutic hypothermia. Pediatr Res. 2014;75(3): 431-5.

24 Shellhaas RA, Kushwaha JS, Plegue MA, Selewski DT, Barks JD. An evaluation of cerebral and systemic predictors of 18 -month outcomes for neonates with hypoxic ischemic encephalopathy. J Child Neurol. 2015;30(11): 1526-31.

25 Sarafidis K, Tsepkentzi E, Agakidou E, Diamanti E, Taparkou A, Soubasi V, et al. Serum and urine acute kidney injury biomarkers in asphyxiated neonates. Pediatr Nephrol. 2012; 27(9):1575-82.

26 Cleper R, Shavit I, Blumenthal D, Reisman L, Pomeranz G, Haham A, et al. Neonatal acute kidney injury: recording rate, course, and outcome: one center experience. J Matern Fetal Neonatal Med. 2019;32(20):3379-85.

27 Bruel A, Rozé JC, Quere MP, Flamant C, Boivin M, Roussey-Kesler G, et al. Renal outcome in children born preterm with neonatal acute renal failure: IRENEO: a prospective controlled study. Pediatr Nephrol. 2016; 31(12):2365-73.

28 Askenazi DJ, Morgan C, Goldstein SL, Selewski DT, Moxey-Mims MM, Kimmel PL, et al. Strategies to improve the understanding of long-term renal consequences after neonatal acute kidney injury. Pediatr Res. 2016;79(3): 502-8. 